\title{
Mina Bissell focuses on context
}

or over three decades, Mina Bissell, a Distinguished Scientist at the Lawrence Berkeley National Laboratory, has investigated how cells interact with their environment. Her research has helped to reshape cell culture methods as well as our understanding of cell fate and tumorigenesis. Her work in uncovering the roles of the ECM has been widely recognized, and in March she was named the winner of the 2011 Jill Rose Award from the Breast Cancer Research Foundation. Bissell recently spoke to the JCI about her experiences.

JCI: How did you decide to focus your career on cancer research?

Bissell: I didn't decide; it just happened! I majored in chemistry and then became a bacterial geneticist. As a postdoctoral fellow, I was working with the first known potent oncogenic virus (Rous sarcoma virus) in the molecular biology department of UC Berkeley. We were using chicken embryo fibroblasts in culture, and coming from a completely different background and not having been taught textbook biology, I started questioning whether we could answer the questions we were asking the way we were doing experiments on flat dishes and in incubators that changed their $\mathrm{pH}$ and temperatures every time we opened them. That was the beginning of my interest in how tissues remember how to be what they are. We have 10 trillion cells in our body with identical genetic material, so how do organs and tissues have the wisdom to keep their "fingerness" or "eyeness" or "breastness" or "prostateness?" Based on almost 40 years of research, I now believe that the architecture of the tissue determines its function and everything in the cell, tissue, organ, and organism has to be integrated to make these 10 trillion cells function within each organ. And that is what starts unraveling in cancer. That became a really exciting intellectual problem for me - I thought that we won't understand cancer until we understand normal.

JCI: What do you think are the outstanding questions in breast cancer research?

Bissell: There are two related opportunities: we need to understand generally how to prevent cancer and its progression. We also need to increase our understanding of the role of microenvironment. The general public believes that there is a lot of cancer, but I ask, why is cancer so rare? I'd argue that we all have a lot of precancerous lesions, small tumors, etc., and some apparently from an early age, but they don't go anywhere; they do not become overt cancers and they are not discovered unless someone does an autopsy and finds these atypias. I think the microenvironment exerts a very strong influence on cells within the tissues telling them to remain what they are and prevents these premalignant or even small tumors from becoming full-blown disease. So we

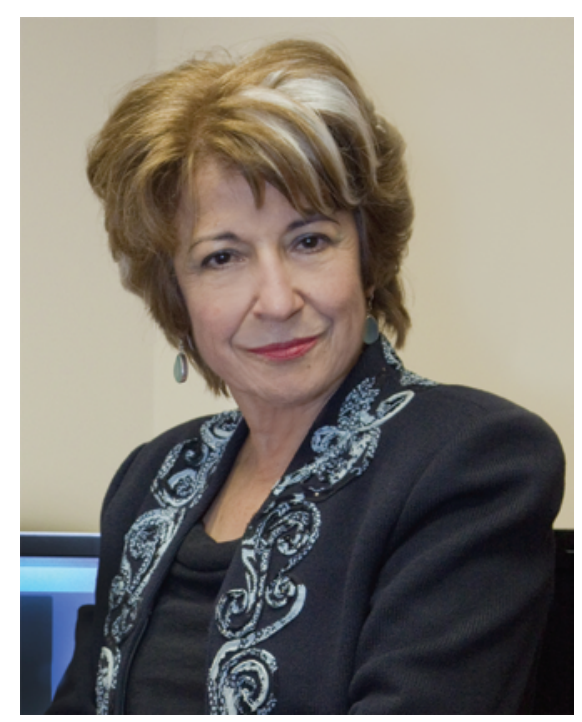

need to understand the why and the how, and we also need to learn how to treat cancer like a chronic disease.

JCI: You've spent most of your career at the Lawrence Berkeley National Laboratory. Do you think that unique environment shaped your approach to science or your successes in any way?

Bissell: I'm very grateful to the NIH, and I'm very grateful to the NCI and to the tumor microenvironment funding (I now even have a Merit award!). However, when I started my career, you had to create half of your data and conform to the dogma of that day before you could get an NIH grant. The Department of Energy and the Berkeley Labs were really innovative despite the perceptions to the contrary. One of the amazing things was that when I started, and even now, they really supported creative scientists. Once they decided that someone had a vision, had energy, had innovation, they tried to support you. So even when I got better known and got other job offers, I didn't want to leave. This is because I felt that the atmosphere at Berkeley lab is different than regular universities, in part because you have access to physicists, bioinformaticists, and engineers.

JCI: So you think that a multi-disciplinary approach is important?

Bissell: I used to be criticized for being "all over the place," but now that connecting different disciplines is in vogue, people have realized it is a useful and even necessary approach, because we can't work on one molecule at a time if we want to address the complexities of biological systems. At the same time, you can't just go to a physicist and say "solve our problem," because they first have to really digest the biology. So of course I do think it is important, and I believe that is a way of thinking about biology that's not yet in our textbooks or medical books, and I find this really distressing. But luckily I have a lot of wonderful and successful former students and fellows in different universities and biotech companies, so I think it will continue to catch on.

JCI: You've recently been named the recipient of the 2011 Jill Rose Award. What does this prize mean to you?

Bissell: I feel very honored and very touched by this and other honors I have received in the last few years. I feel that this is an indication of why one should persist, and furthermore, how important it is to buckle down and do the work. We couldn't just go around saying, "I'm right, I'm right!" We had to do the work and generate the data.

JCI: Did you know that there's a "Dr. Mina Bissell Fan Club (MBFC)” Facebook page?

Bissell: [Laughs] I'm very honored, but I don't know who started it, and I don't know what's in it. I've never looked at Facebook! You know, someone said to me, "You're in Wikipedia!" and I had no idea. I did check that, however, and I still don't know who started it except that the person was in Sweden! Fortunately one of my former fellows went in to make sure it was accurate and more or less current. I wouldn't have known how!

\section{Kathryn Claiborn}

